\title{
Characterization of 19 new microsatellite loci for the Omani barb Garra barreimiae from 454 sequences
}

\author{
Sandra Kirchner ${ }^{1 *}$, Thomas Weinmaier ${ }^{2}$, Thomas Rattei ${ }^{2}$, Helmut Sattmann $^{3}$ and Luise Kruckenhauser ${ }^{4}$
}

\begin{abstract}
Background: Garra barreimiae is a cyprinid fish from the southeastern Arabian Peninsula, which inhabits regularly desiccating wadis and survives in isolated ponds or underground. In 1984 a cave-dwelling population was found in the Al Hoota cave system and previous genetic analyses revealed some differentiation with limited gene flow between the surface populations and the cave population. Since no suitable markers are available for evaluation of gene flow between the cave population and the adjacent surface populations, we focused on designing and establishing novel microsatellite markers from next generation sequencing data.
\end{abstract}

Findings: 19 microsatellite markers containing di- and tetranucleotide simple sequence repeats were developed from 454 sequences. Forty-four individuals from two surface populations (Wadi Al Falahi and Misfat Al Abriyeen) of G. barreimiae (sampling permission number 13/2012, export permission number 29/2012) were used for analyses and characterization of the loci. On average, the number of alleles per locus is 7.6 (range: 2-20). Two markers displayed indication of linkage disequilibrium in both populations (DL6X, 9XNC). Significant deviation from Hardy-Weinberg equilibrium was observed at four loci in the Misfat Al Abriyeen population (2PUM, 88CM, 1EHE, 3Z7M) and at two loci in the Wadi Al Falahi population (QLIM, 3 N43). Three of the microsatellite loci were significant for null alleles in one of the two populations (Misfat Al Abriyeen: CJHG; Wadi Al Falahi: PH8A, 3ROZ). Expected and observed heterozygosities ranged from 0 to 95.0\% respectively from 0 to 95.8\% (Wadi Al Falahi) and from 0 to $89.1 \%$ respectively from 0 to $95.0 \%$ (Misfat Al Abriyeen). Fourteen of these markers were successfully cross-amplified in G. rufa.

Conclusion: This 19 microsatellite loci provide a useful tool to understand the structure and genetic differences of populations. Moreover, these markers will help to evaluate species delimitation in G. barreimiae and potentially even in related species.

Keywords: Garra barreimiae, Garra rufa, Oman, microsatellites, 454 sequences

\section{Findings}

The cyprinid Garra barreimiae Fowler \& Steinitz (1956) is endemic to the southeastern Arabian Peninsula, where it is common in ponds and rivulets of the Hajar mountains in the northern Oman and the United Arab Emirates [1] [2]. Most of these wadis dry out during summer and are only occasionally flooded, so the fish have to survive in isolated ponds or underground. In 1980 a hypogean troglomorphic population of this species was found in the $\mathrm{Al}$

\footnotetext{
* Correspondence: sandra.kirchner@nhm-wien.ac.at

${ }^{1}$ Natural History Museum Vienna, Central Research Laboratories, Burgring 7, 1010 Vienna, Austria

Full list of author information is available at the end of the article
}

Hoota cave system near Al Hamra [3]. All adult individuals in this population are missing externally visible eyes, and the optic lobes are reduced. In addition, the squamation is weak and they lack pigmentation [3]. Until now the $\mathrm{Al}$ Hoota cave population is the only known troglomorphic form of G. barreimiae. Previous genetic analyses on the basis of the mitochondrial control region revealed a differentiation between cave and surface populations and possible gene flow as indicated by shared haplotypes [4]. The separation is not complete, and there seems to be limited gene flow from the cave to the adjacent surface populations. The small genetic differentiation between the two forms indicates that the troglomorphic cave 
population is of quite recent origin [4]. According to current taxonomy, the species comprises three subspecies: Garra barreimiae barreimiae, which can be found throughout the northern Oman, G. b. gallagheri Krupp [5] found only at one location in northern Oman and G. $b$. shawkahensis Banister \& Clarke [1], found north of the United Arab Emirates [5]. Investigations of Kruckenhauser et al. [4] revealed that the first two subspecies are genetically distinct based on mtDNA analyses. Moreover, they found an additional clearly separated clade on the northeastern slope of the Hajar Mountains, suggesting that Garra barreimiae may be comprised of more than one species. In the present study, we analysed individuals of $G$. barreimiae from two surface populations: Misfat $\mathrm{Al}$ Abriyeen is a locality near the mountain village Misfat, north of Bahla. The fish were collected in the Falaj drainage system, which channels the water through the villages' gardens. About $15 \mathrm{~km}$ southwards from Misfat the small water body Wadi Al Falahi, a natural drain from the surrounding mountains, is located. Both localities hold numerous individuals of G. barreimiae. The individuals of G. $r u f a$, which were used to test whether cross-species amplification works in another species of the genus, were commercially acquired.

To estimate gene flow between the different morphs and populations for this - in terms of evolutionary biology highly interesting fish species specific genetic markers are needed. The method of choice for this purpose are microsatellite markers, which however, were up to now not available for G. barreimiae [6]. Next generation sequencing allows the isolation of a high number of microsatellite loci at moderate costs [7] and multiplexing of loci enables high through-put genotyping. Here, we describe the development of 19 microsatellite markers for G. barreimiae using the new technological advantages.

For DNA extraction, we used tissue from a finclip taken from one specimen of the cave population. We followed the DNA-extraction protocol (GEN-IAL First-DNA Alltissue DNA-Kit, GEN-IAL GmbH, Germany) and isolated genomic DNA. Approximate 500 ng DNA was used for $1 / 20$ of a plate for 454 sequencing on a Roche/454 GSFLX sequencer at the Genomics Core Facility University of Leicester, UK. Sequencing generated a total of 36126 reads. The sequence reads were assembled into 193 contigs with size ranging from $500-3547$ bp by using Newbler (454 Life Sciences, Roche, Switzerland). Of the remaining 35503 non-assembled reads, we also considered 29418 high quality reads (3' trimmed until quality 20; average quality 20; minimal length $100 \mathrm{bp}$ ) with sizes between 100 and $731 \mathrm{bp}$.

We designed primers with the program QDD version 2.1 [8], which incorporates the computer language Perl and the programs ClustalW2 [9], Primer3 [10] and BLAST $+[11]$. Criteria used to select microsatellite loci included: appropriate product size (between 75 and $320 \mathrm{bp})$ and a minimum repeat motif of five subunits consisting of two to six nucleotides. For the primer design, conditions were set for a 20 bp optimum length (18-27 bp) and optimum temperature of $60.6^{\circ} \mathrm{C}$, allowing a $12^{\circ} \mathrm{C}$ temperature difference between the two primers of a primer pair $\left(52-63^{\circ} \mathrm{C}\right)$. Optimum GCcontent was set on $50 \%(20-80)$. After these selections 919 contigs and single reads with at least one microsatellite and featuring suitable primers fulfilled the requirements. After selection of only di- and tetranucleotide repeats and sequences containing just one microsatellite, 767 sequences remained for further analysis. During primer selection, QDD grouped the primers into different primer classes (A to G). We chose only the two most restrictive classes, which fulfill the following conditions: (1) allowing assembled microsatellites, (2) not allowing nanosatellites in the primer region and (3) allowing nanosatellites in the flanking region, i. e., the region between the primer binding site and the actual microsatellite sequence (468 sequences). The final step was to select only sequences, whose microsatellites comprise a motif repeated eight to 22 times. After all this exclusions, 94 sequences retained for primer designing.

We selected primers with a high GC-content displaying no primer dimers and similar annealing temperature (comparing forward- and reverse primers of each primer pair). We tested the potential primer sequences against the original sequence with BioEdit version 7.2.5 [12]. In case we found no primers with matching annealing temperatures, we used NCBI Primer-BLAST [13] to find alternate primer sequences. We checked the primers for dimers with Amplify [14] and manually redesigned the primer sequences if necessary.

Finally 36 different microsatellite loci were left, which were first screened for consistent amplification via PCR. Those primers amplifying a product and working in different samples were chosen for microsatellite analyses of individuals from two surface populations (Wadi $\mathrm{Al}$ Falahi $\mathrm{N}=24$, Misfat Al Abriyeen $\mathrm{N}=20$ ). These individuals were collected in accordance with the local legislation of the Sultanate of Oman (Ministry of Environment and Climate Affairs: sampling permission number 13/ 2012, export permission number 29/2012).

Since we wanted to perform multiplex PCRs, we made use of the program Multiplex Manager version 1.0 [15], a tool for managing and optimizing a multiplex set by minimising the total number of reactions, minimising the annealing temperature differences among primer pairs within each reaction and maximising the size differences between the products amplified from the various loci within one reaction. The remaining 25 markers were put into three different multiplex reactions which were used for electrophoresis. For amplification 
these multiplex reactions were further divided as some loci showed a better readable electrophoresis pattern when amplified with a multiplex kit (QIAGEN Multiplex PCR Kit, QIAGEN, Netherlands) and others using the TopTaq kit (TopTaq DNA Polymerase, QIAGEN, Netherlands).
Multiplex PCR was performed either using the multiplex kit in $10 \mu \mathrm{l}$ reaction volumes $(1 \mu \mathrm{l} \mathrm{DNA}, 2.5 \mu \mathrm{l}$ QIAGEN multiplex PCR mastermix, $1 \mu$ primermix, $1 \mu \mathrm{l}$ Q-solution and $4.5 \mu \mathrm{l} \mathrm{AD}$ ), or using the TopTaq kit also with a reaction volume of $10 \mu \mathrm{l}(0.5 \mu \mathrm{l}$ DNA, $2 \mu \mathrm{l}$

Table 1 Primer sequences, repeat motifs, amplification parameters and accession numbers of microsatellite loci in Garra barreimiae

\begin{tabular}{|c|c|c|c|c|c|c|c|}
\hline Locus name & Primer sequences $5^{\prime}$ - > $3^{\prime}$ & Primer labelling & Primer C (pMol) & Repeat motif & Reaction & $\mathrm{T}_{\mathrm{a}}\left({ }^{\circ} \mathrm{C}\right)$ & Accession Nr. \\
\hline \multirow[t]{2}{*}{ QLIM } & F-ACGGTTGATAGAGCCACTGAC & & 2 & $A G$ & MPR1 & $65 / 60$ & KM099076 \\
\hline & R-ACTGTCGAGCAATGCAACAC & PET & 2 & & & & \\
\hline \multirow[t]{2}{*}{$7 \mathrm{GHL}$} & F-GTATTACCGTGGTGATGTGGC & PET & 4 & AGAT & MPR1 & $65 / 60$ & KM099077 \\
\hline & R-GCGGCGTAGAAATCTGACTG & & 4 & & & & \\
\hline \multirow[t]{2}{*}{ PH8A } & F-ACACTTCCAAAACGGTCGC & $\mathrm{VIC}$ & 2 & AGAT & MPR1 & $65 / 60$ & KM099078 \\
\hline & R-CGGAGCAAACCCAGTGACTA & & 2 & & & & \\
\hline \multirow[t]{2}{*}{ UHPE } & F-ACCACAGCCAGTCAGATATGC & & 2 & $A C$ & MPR1 & $65 / 60$ & KM099079 \\
\hline & R-GCTCAACAAGCTGAACTCCG & 6-FAM & 2 & & & & \\
\hline \multirow[t]{2}{*}{ JQSO } & F-TTGGCTGGAGCGATGGCTG & 6-FAM & 2 & $A C$ & MPR1 & $65 / 60$ & KM099080 \\
\hline & R-AGGGCTACATCACAGACTCAC & & 2 & & & & \\
\hline \multirow[t]{2}{*}{ DL6X } & F-GTGACACATTTGGATAATGAATCAGC & NED & 2 & $A C$ & TTR1 & $65 / 60$ & KM099081 \\
\hline & R-AGCTGGCCTAGATACCTGAC & & 2 & & & & \\
\hline \multirow[t]{2}{*}{ FYP9 } & F-CGTCGACCAACGGACTAACG & NED & 2 & $A C$ & TTR1 & $65 / 60$ & KM099082 \\
\hline & R-GACCGACATCAATCACGCGCT & & 2 & & & & \\
\hline \multirow[t]{2}{*}{ HOLN } & F-ACTGCGCTCGTACCCTATG & 6-FAM & 2 & $A C$ & TTR1 & $65 / 60$ & KM099083 \\
\hline & R-CAGCAGCCGGTAAATAGCTG & & 2 & & & & \\
\hline \multirow[t]{2}{*}{ JMLR } & F-CGATCAGATATGCAATGGCAG & & 2 & $A C$ & MPR2 & $64 / 59$ & KM099084 \\
\hline & R-GTGATCAGGCCTGTGTAAACG & NED & 2 & & & & \\
\hline \multirow[t]{2}{*}{$\mathrm{CJHG}$} & F-CTGACCTGATCTACGAAACCG & 6-FAM & 1.6 & $A C$ & MPR2 & $64 / 59$ & KM099085 \\
\hline & R-TGAGTTGTGGAGTCCAGCG & & 1.6 & & & & \\
\hline \multirow[t]{2}{*}{$3 Z 71$} & F-CGAGGTTTGGTTCCTCTTCTC & $\mathrm{VIC}$ & 1.6 & $A G$ & MPR2 & $64 / 59$ & KM099086 \\
\hline & R-CAGCCTGGCTAACTCTGAGC & & 1.6 & & & & \\
\hline \multirow[t]{2}{*}{ 9XNC } & F-GCCAGTCAGTAGCTGCAAC & PET & 1.6 & $A C$ & TTR2 & $64 / 59$ & KM099087 \\
\hline & R-GTTGTGCTATTCTGTGTAAGACC & & 1.6 & & & & \\
\hline \multirow[t]{2}{*}{$3 \mathrm{~N} 43$} & F-GTGCTGCTTTCCTTCTTCG & PET & 2 & $A C$ & TTR2 & $64 / 59$ & KM099088 \\
\hline & R-ACCAGGAGCCGATCCATAAAC & & 2 & & & & \\
\hline \multirow[t]{2}{*}{$1 \mathrm{EHE}$} & F-GCAGATGTAGTCAATTGACATGC & 6-FAM & 1 & $A C$ & TTR2 & $64 / 59$ & KM099089 \\
\hline & R-GCGAGGGCTTGAACTGATAC & & 1 & & & & \\
\hline \multirow[t]{2}{*}{$88 \mathrm{CM}$} & F-CTGTCGTCCATGGCTGTACC & $\mathrm{VIC}$ & 1 & $A G$ & TTR2 & $64 / 59$ & KM099090 \\
\hline & R-AGGACTGGCATGTTTGCATT & & 1 & & & & \\
\hline \multirow[t]{2}{*}{$16 G 2$} & F-AGCATCTGAGCATTCTCCTG & $\mathrm{VIC}$ & 3 & AT & MPR3 & $60 / 54$ & KM099091 \\
\hline & R-CCAAACGGTACGTCTTATGG & & 3 & & & & \\
\hline \multirow[t]{2}{*}{ 3ROZ } & F-TGGTGGTTTATATGCAGTCTGA & $\mathrm{VIC}$ & 4 & $A C$ & MPR3 & $60 / 54$ & KM099092 \\
\hline & R-ACCCAAGGATGTTGTGTCCG & & 4 & & & & \\
\hline \multirow[t]{2}{*}{ CB75 } & F-CCATGCATCTACCTACCCAC & PET & 2 & AGGT & MPR3 & $60 / 54$ & KM099093 \\
\hline & R-TGATCAAATAGATGGTGGCTG & & 2 & & & & \\
\hline \multirow[t]{2}{*}{ 2PUM } & F-CATGCCAATTCACTCATTCC & NED & 1 & $A G$ & TTR3 & $60 / 54$ & KM099094 \\
\hline & R-ACGTCACGTGTTGTCTATCTTG & & 1 & & & & \\
\hline
\end{tabular}


Table 2 Population genetic parameters of microsatellite loci of Garra barreimiae and cross-species amplification results

\begin{tabular}{|c|c|c|c|c|c|c|c|c|c|c|c|c|c|c|}
\hline Locus name & N MF & N WF & Size (bp) & $\mathrm{N}_{\mathrm{A}}$ & $\mathrm{H}_{\mathrm{e}} \mathrm{MF}$ & $\mathrm{H}_{\mathrm{o}} \mathrm{MF}$ & Oosterhout MF & HW p-value MF & $\mathrm{H}_{\mathrm{e}} \mathrm{WF}$ & $\mathrm{H}_{\mathrm{o}} \mathrm{WF}$ & Oosterhout WF & HW p-value WF & $\mathrm{F}_{\mathrm{ST}}$ & CA \\
\hline$\overline{\text { QLIM }^{C}}$ & 20 & 24 & $88-92$ & 3 & 0.00 & 0.00 & 0 & NV & 19.42 & 20.83 & -0.108 & 0 & 0.059 & 22 \\
\hline $7 \mathrm{GHL}$ & 20 & 24 & $166-250$ & 19 & 89.10 & 90.00 & -0.022 & 0.571 & 93.09 & 95.83 & -0.027 & 0.777 & $0.025^{*}$ & 11 \\
\hline $\mathrm{PH} 8 \mathrm{~A}^{\mathrm{C}}$ & 20 & 24 & $126-188$ & 15 & 86.03 & 95.00 & -0.076 & 0.634 & 91.58 & 75.00 & 0.082 & 0.995 & $0.020^{*}$ & 21 \\
\hline $\mathrm{UHPE}^{\mathrm{C}}$ & 20 & 24 & $89-101$ & 7 & 35.26 & 30.00 & 0.107 & 0.872 & 54.43 & 62.50 & -0.087 & 0.437 & $0.071^{*}$ & 20 \\
\hline $\mathrm{JQSO}^{\mathrm{C}}$ & 20 & 24 & $147-169$ & 7 & 74.49 & 75.00 & -0.021 & 0.092 & 75.89 & 62.50 & 0.077 & 0.966 & $0.160^{* *}$ & 20 \\
\hline DL6X & 20 & 24 & $112-126$ & 8 & 60.00 & 65.00 & -0.069 & 0.250 & 59.75 & 70.83 & -0.120 & 0.273 & $0.156^{* *}$ & 19 \\
\hline $\mathrm{FYP9}^{\mathrm{C}}$ & 20 & 24 & $169-235$ & 20 & 78.46 & 90.00 & -0.096 & 0.477 & 95.04 & 87.50 & 0.031 & 0.793 & $0.068^{* *}$ & 22 \\
\hline HOLN & 20 & 24 & $191-233$ & 7 & 59.49 & 65.00 & -0.067 & 0.128 & 39.89 & 41.67 & -0.033 & 0.419 & $0.195^{* *}$ & 22 \\
\hline$J M L R^{C}$ & 20 & 24 & $93-99$ & 4 & 57.44 & 65.00 & -0.064 & 0.360 & 71.37 & 70.83 & -0.007 & 0.818 & $0.120^{* *}$ & 20 \\
\hline $\mathrm{CJHG} \mathrm{C}^{\mathrm{C}}$ & 20 & 24 & $198-215$ & 7 & 54.23 & 35.00 & 0.172 & 0.968 & 77.66 & 75.00 & -0.002 & 0.588 & $0.194^{* *}$ & 21 \\
\hline $3 Z 71^{c}$ & 20 & 24 & $123-127$ & 2 & 29.62 & 35.00 & -0.194 & 0.000 & 0.00 & 0.00 & 0 & NV & $0.170^{*}$ & 22 \\
\hline $9 X N C^{C}$ & 20 & 24 & $101-112$ & 6 & 71.67 & 70.00 & -0.012 & 0.594 & 74.20 & 70.83 & 0.007 & 0.589 & $0.061^{*}$ & 22 \\
\hline 3 N43 & 20 & 24 & $182-184$ & 2 & 0.00 & 0.00 & 0 & NV & 28.37 & 33.33 & -0.184 & 0 & $0.135^{*}$ & 22 \\
\hline $1 \mathrm{EHE}^{\mathrm{C}}$ & 20 & 24 & $106-112$ & 4 & 68.08 & 80.00 & -0.106 & 0.000 & 63.03 & 62.50 & 0.004 & 0.068 & $0.176^{* *}$ & 22 \\
\hline $88 \mathrm{CM}^{\mathrm{C}}$ & 20 & 24 & $190-198$ & 6 & 40.90 & 45.00 & -0.069 & 0.000 & 73.40 & 54.17 & 0.120 & 0.995 & $0.216^{* *}$ & 21 \\
\hline $16 G 2^{c}$ & 20 & 24 & $115-137$ & 8 & 58.21 & 60.00 & -0.012 & 0.684 & 71.45 & 62.50 & 0.048 & 0.781 & $0.282^{* *}$ & 22 \\
\hline $3 \mathrm{ROZ}$ & 20 & 24 & $262-276$ & 5 & 14.23 & 5.00 & 0.172 & 0.923 & 56.34 & 4.55 & 0.386 & 1.000 & $0.172^{*}$ & 0 \\
\hline CB75 & 20 & 24 & $171-199$ & 7 & 51.41 & 45.00 & 0.067 & 0.767 & 68.17 & 75.00 & -0.069 & 0.074 & 0.005 & 2 \\
\hline $2 P \cup M^{C}$ & 20 & 24 & $152-176$ & 8 & 38.33 & 45.00 & -0.240 & 0.000 & 77.66 & 87.50 & -0.082 & 0.212 & $0.121^{* *}$ & 22 \\
\hline
\end{tabular}

$\mathrm{N}$ number of individuals analysed, Ta $\left({ }^{\circ} \mathrm{C}\right)$ annealing temperature, NA number of alleles, MF Misfat Al Abriyeen, WF Wadi Al Falahi, $\mathrm{H}_{\mathrm{e}}$ expected heterozygosity in\%, $\mathrm{H}_{\mathrm{o}}$ observed heterozygosity in\%, null allele estimates (Oosterhout values), HW p-value probability for deviation from Hardy-Weinberg equilibrium, $\mathrm{F}_{\mathrm{ST}}$ values (*indicates significant values at $\mathrm{p}<0.05$ and ${ }^{*}$ at $\mathrm{p}<0.001$ ); loci marked with ${ }^{\mathrm{C}}$ were positive and polymorphic in Garra rufa; CA number of individuals positive in cross-species amplification (tested in 22 individuals of $G$. rufa). 
Q-solution, $1 \mu \mathrm{l}$ buffer, $200 \mu \mathrm{M}$ dNTPs, $1500 \mu \mathrm{M} \mathrm{Mg++}$, $0.5 \mu \mathrm{l}$ primermix, 0.5 units TopTaq-polymerase and $5.1 \mu \mathrm{l} \mathrm{AD}$ ). According to the three different multiplex reactions, those PCRs were named MPR $1 / 2 / 3$ for multiplex kit reaction $1 / 2 / 3$ or TTR $1 / 2 / 3$ for TopTaq kit reaction $1 / 2 / 3$. We followed a two-step cycling protocol for each reaction as follows: initial denaturation at $95^{\circ} \mathrm{C}$ for $15 \mathrm{~min}, 2$ cycles denaturation at $94^{\circ} \mathrm{C}$ for $30 \mathrm{~s}$, annealing at $65^{\circ} \mathrm{C}(\mathrm{R} 1), 64^{\circ} \mathrm{C}(\mathrm{R} 2), 60^{\circ} \mathrm{C}(\mathrm{R} 3)$ for $90 \mathrm{~s}$, extension at $72^{\circ} \mathrm{C}$ for $60 \mathrm{~s}$. This was followed by 35 cycles denaturation at $94^{\circ} \mathrm{C}$ for $30 \mathrm{~s}$, annealing at $60^{\circ} \mathrm{C}(\mathrm{R} 1), 59^{\circ} \mathrm{C}$ (R2), $54^{\circ} \mathrm{C}$ (R3) for $90 \mathrm{~s}$, extension at $72^{\circ} \mathrm{C}$ for $60 \mathrm{~s}$ and a final extension at $60^{\circ} \mathrm{C}$ for $30 \mathrm{~min}$. PCR products were diluted 1:20 with $\mathrm{AD}$, multiplexed according to the reactions and added to a mixture of $\mathrm{Hi}-\mathrm{Di}$ formamide and size standard (Gene Scan ${ }^{\text {Tx }} 500$ LIZ, Life Technologies, USA). After a denaturation at $94^{\circ} \mathrm{C}$ for $4 \mathrm{~min}$, the products were run on a 3130xl Sequence Analyzer (Applied Biosystems, USA).

After fragment analyses and testing for polymorphic loci, 19 different microsatellite markers proved to be suitable for genotyping. Primer sequences, PCR conditions, and their respective GenBank accession numbers are listed in Table 1. The alleles of all 19 loci (44 individuals) obtained from the resulting electropherograms were identified and binned with GENEMAPPER v5.0 (Applied Biosystems, USA) and manually reviewed. For each population, we estimated the observed $\left(\mathrm{H}_{\mathrm{o}}\right)$ and expected $\left(\mathrm{H}_{\mathrm{e}}\right)$ heterozygosities and tested for linkage disequilibria and deviations from Hardy-Weinberg equilibria using Genepop v 4.2.2 [16]. Subsequently we used Microchecker v 2.2 [17] to test for null alleles. We calculated the fixation Index with the program ARLEQUIN v3.5 [18]. All loci proved to be polymorphic in both populations. Results of population genetic analyses are shown in Table 2 . For the 19 examined loci, the number of alleles per locus ranged from two to 20. Two loci (DL6X and 9XNC) showed a significant deviation on the $5 \%$ level from linkage equilibrium in both populations (Wadi Al Falahi and Misfat $\mathrm{Al}$ Abriyeen). Microchecker results revealed evidence for null alleles in one locus (CJHG; frequency after Oosterhout: 0.172) in the population Misfat Al Abriyeen and two loci (PH8A, 3ROZ; frequency after Oosterhout: 0.0815, 0.3868) in the population Wadi Al Falahi. However, since none of these loci showed a constant significant deviation in both populations, we did not exclude the loci from our analyses. Considering each population separately, one locus (CJHG) in the Misfat $\mathrm{Al}$ Abriyeen population and 4 loci (PH8A, JQSO, 88CM, 3ROZ) in the Wadi Al Falahi population were not in Hardy-Weinberg equilibrium displaying a deficit of heterozygotes, which is likely due to the occurrence of potential null alleles in the markers CJHG, PH8A and 3ROZ. None of the loci showed a significant deviation in the population Misfat Al Abriyeen as well as in the population Wadi Al Falahi. Heterozygosities at some loci were very low (UHPE) or even zero (3Z71, QLIM, 3 N43) for one of the populations. For the loci 3Z71, QLIM, 3 N43 this is due to the fact that the numbers of alleles are small (2-3) and in each case one of the two populations possessed only one of the alleles. In the locus UHPE the number of alleles is higher (7), but in each of the two populations one allele occurs with high frequency and most individuals are thus homozygous. The fixation index of $12.83 \%$ shows high degree of variation between the two populations (see Table 2 for single loci $\mathrm{F}_{\mathrm{ST}}$ values).

All markers were tested for cross-species amplification in 22 individuals of G. rufa (fin clips were taken from bred individuals kept in the Zoo Vienna). Out of the 19 loci, 14 were positive in G. rufa and proved to be polymorphic in at least $75 \%$ of the individuals (Table 2). Thus, these 14 loci could be used for population genetic analyses in the commercially exploited species G. rufa.

The set of microsatellite loci isolated and tested in the present study will be useful DNA markers for further population genetic studies of G. barreimiae and might also be used in other species of this genus. The results from using these microsatellite markers will provide deeper insights into the species' population structure and its genetic diversity. Furthermore, it will be of utmost interest to use these loci in the cave population of G. barreimiae and estimate gene flow between the cave and the surface population. This will help to evaluate species delimitation of G. barreimiae and to assess whether any cryptic species exist besides G. barreimiae.

\section{Competing interests}

All authors declare that they have no competing interests.

\section{Authors' contribution}

LK and SK participated in the study conception. TW and TR supervised the bioinformatic analyses, SK carried out most laboratory work, searched and characterized microsatellite loci, LK and SK analysed the data and wrote the manuscript. HS initiated the study and provided the samples. All authors read and approved the final manuscript.

\section{Acknowledgements}

We thank Wolfgang Arthofer (University of Innsbruck) for coordinating the genome sequencing, Johannes Rath and Christian Baranyi from the University of Vienna for providing help with the Sequence Analyzer, Elisabeth Haring (NHM Vienna) for help with sample collection and critical discussions, Frank Zachos (NHM Vienna) for help and support with population genetic analyses and Toni Weissenbacher (Zoo Vienna) for providing the G. rufa samples. Special thanks to Lukas Raneburger for helpful comments and support. We want to express our gratitude to the Ministry of Environment and Climate Affairs of Oman for their cooperation, support and the sampling permits and to Michael Robinson and Reginald Victor, zoologists at the Sultan Qaboos University in Muscat, for their intellectual input. The Federal Ministry for Transport, Innovation and Technology Austria provided financial support in the course of a FEMtech practical.

\section{Author details}

${ }^{1}$ Natural History Museum Vienna, Central Research Laboratories, Burgring 7, 1010 Vienna, Austria. ${ }^{2}$ Division of Computational Systems Biology, Department of Microbiology and Ecosystem Science, University of Vienna, 
Althanstraße 14, 1090 Vienna, Austria. ${ }^{3}$ Third Zoological Department, Natural History Museum Vienna Austria, Burgring 7, 1010 Vienna, Austria. ${ }^{4}$ Natural History Museum Vienna, Central Research Laboratories, Burgring 7, 1010 Vienna, Austria.

Received: 17 March 2014 Accepted: 5 August 2014

Published: 12 August 2014

\section{References}

1. Banister KE, Clarke MA: The freshwater fishes of the Arabian peninsula. In Sci Results Oman Flora Fauna Surv 1975 J Oman Stud Spec Report No 1. Edited by Harrison DL. Muscat, Sultanate of Oman: Ministry of Information and Culture; 1977:111-154 [The Journal of Oman Studies Special Report. No. 1].

2. Krupp F: Fishes of Saudi Arabia: freshwater fishes of Saudi Arabia and adjacent regions of the Arabian Peninsula. Fauna Saudi Arab 1983, 5:568-636.

3. Banister KE: A subterranean population of Garra barreimiae (Teleostei: Cyprinidae) from Oman, with comments on the concept of regressive evolution. J Nat Hist 1984, 18:927-938.

4. Kruckenhauser L, Haring E, Seemann R, Sattmann H: Genetic differentiation between cave and surface-dwelling populations of Garra barreimiae (Cyprinidae) in Oman. BMC Evol Biol 2011, 11:172.

5. Krupp F: Freshwater Fishes of the Wadi Batha drainage. J Oman Studies Spec Rept 1988, 3:401-404.

6. Guichoux E, Lagache L, Wagner S, Chaumeil P, Léger P, Lepais O, Lepoittevin C, Malausa T, Revardel E, Salin F, Petit RJ: Current trends in microsatellite genotyping. Mol Ecol Resour 2011, 11:591-611.

7. Gardner MG, Fitch AJ, Bertozzi T, Lowe AJ: Rise of the machinesrecommendations for ecologists when using next generation sequencing for microsatellite development. Mol Ecol Resour 2011, 11:1093-1101.

8. Meglécz E, Costedoat C, Dubut V, Gilles A, Malausa T, Pech N, Martin J-F: QDD: a user-friendly program to select microsatellite markers and design primers from large sequencing projects. Bioinformatics 2010, 26:403-404.

9. Larkin MA, Blackshields G, Brown NP, Chenna R, McGettigan PA, McLarkin MA, McWilliam H, Valentin F, Wallace IM, Wilm A, Lopez R, Thompson JD, Gibson TJ, Higgins D: ClustalW and ClustalX version 2. Bioinformatics 2007, 23:2947-2948

10. Untergasser A, Cutcutache I, Koressaar T, Ye J, Faircloth BC, Remm M, Rozen S: Primer3-new capabilities and interfaces. Nucleic Acids Res 2012, 40:e115.

11. Camacho C, Coulouris G, Avagyan V, Ma N, Papadopoulos J, Bealer K, Madden TL: BLAST+: architecture and applications. BMC Bioinformatics 2009, 10:421.

12. Hall TA: BioEdit: a user-friendly biological sequence alignment editor and analysis program for Windows 95/98/NT. Nucleic Acids Symp Ser 1999, 41:95-98.

13. Ye J, Coulouris G, Zaretskaya I, Cutcutache I, Rozen S, Madden T: PrimerBLAST: A tool to design target-specific primers for polymerase chain reaction. BMC Bioinformatics 2012, 13:134.

14. Engels B: Amplify - a freeware Macintosh program for simulating and testing polymerase chain reactions. [http://engels.genetics.wisc.edu/amplify/]

15. Holleley CE, Geerts PG: Multiplex Manager 1.0: a cross-platform computer program that plans and optimizes multiplex PCR. Biotechniques 2009, 46:511-517.

16. Rousset F: Genepop'007: a complete reimplementation of the Genepop software for Windows and Linux. Mol Ecol Resour 2008, 8:103-106.

17. Van Oosterhout C, Hutchinson WF, Wills DPM, Shipley P: Micro-Checker: Software for Identifying and Correcting Genotyping Errors in Microsatellite Data. Mol Ecol Notes 2004, 4:535-538.

18. Excoffier L, Laval G, Schneider S: Arlequin ver. 3.5: An integrated software package for population genetics data analysis. Evol Bioinformatics Online 2005, 1:47-50

doi:10.1186/1756-0500-7-522

Cite this article as: Kirchner et al: Characterization of 19 new microsatellite loci for the Omani barb Garra barreimiae from 454 sequences. BMC Research Notes 2014 7:522.

\section{Submit your next manuscript to BioMed Central and take full advantage of:}

- Convenient online submission

- Thorough peer review

- No space constraints or color figure charges

- Immediate publication on acceptance

- Inclusion in PubMed, CAS, Scopus and Google Scholar

- Research which is freely available for redistribution

Submit your manuscript at www.biomedcentral.com/submit
Ciomed Central 